\title{
Research on Economic Sharing Based on PEST and SWOT Model: A Case Study of Mobike
}

\author{
Chao Liu, Gaohong Zhu, and Yanqing Kang \\ School of management engineering, Zheng Zhou University, No. 100 science Avenue, Zheng Zhou, China \\ liuchao@zzu.edu.cn, Gaohong_z@yeah.net,654517068@qq.com
}

Keywords: Internet technology, Sharing economy, Business model, Mobike

\begin{abstract}
With the development of Internet technology, the sharing economy has shown strong potential and application prospects. It brings new production mode, consumption pattern and business model. It will profoundly change the traditional economic form of human society. This paper chooses the Mobike as the research object of sharing economy. Then, it studies the development status and profit driving factors of Mobike by PECT and SWOT model. Through the study of Mobike, this paper deeply analyzes the connotation of sharing economy business model
\end{abstract} and provides reference for the development of Internet + sharing business model in the future.

\section{INTRODUCTION}

Due to the rapid development of Internet technology, the traditional business model has not been able to meet the current economic development (Yiyun Chen, 2015). Master of management Peter F. Drucker once said that the future competition between companies is no longer a single product or service competition, but the business model of competition. The business model appeared in all stages of company development in the process of modern business operation (Russell Belk, 2014). In recent years, many operators realize that the business model innovation plays an important role in the rapid and efficient growth of company. If a company has a good business model, it can develop rapidly. The business model should conform to the characteristics of the company. Therefore, it is necessary to explore the change of business model in the Internet era.

The rapid development of Internet technology promotes the healthy development of the world economy. Meanwhile, it also promotes the development trend of global economic integration. From the perspective of China's development, the sharing economy business model plays an important role in promoting the structural adjustment and industrial transformation. Therefore, company needs to consider how to make full use of the new economic conditions and new business models of the Internet. In this context, business model research has gradually become the focus of experts, scholars and entrepreneurs.

The rest of the paper is organized as follows. Section 2 reviews the related literature. Section 3 describes the development of Mobike and analyzes it by the PEST and SWOT models. In section 4 analyzes the Mobike's profit model. Finally, Section 5 concludes the paper with a summary of the main findings.

\section{LITERATURE REVIEW}

The word "Business Model" was first proposed by
(Schumpeter, J.A, 1939): "Price and output competition is not important, it is important from new business model competition". The definition of the business model was first proposed by (Timmers. P, 1998), which argued that the business model was a framework of products, services and information flows. Meanwhile, Timmers argued that business model included different business activists, potential stakeholders' business activities, and income structures, etc. (Dubosson, M. et al., 2002) argued that the business model was the company in order to carry out value creation and value marketing, which formed the corporate structure and partner network to maintain the revenue flow of customer relationship capital. (Chesbrough, H., 2002) proposed an open innovation theory. He pointed out that companies should create a business model that should match its core technology. Business model innovation was the process of establishing heuristic logic and linking the technology to the underlying economic value.

Business model innovation was the reorganization of existing processes by reorganizing their own resources (Zott, C. and Amit, R., 2010). Business model was the condition, operation mode and means involved in the construction and operation of company (Min Luo, 2005). The value logic of network organization changes due to competitive pressure and technological progress (Qin Wang, 2011).

The purpose of business model innovation was to gain new profit growth points (Weifeng Yao, 2011). Stakeholders were key to the innovation of business model, and the interests of stakeholders were the core of business model innovation. The emergence of ecommerce made some products in the current economic situation under the rapid expansion of the market, which were characterized by low cost, creative and so on (Yang Zheng, Li Yu and Jiangwei Liu,2016).

The rapid development of sharing economy is of great significance to promote the Internet business model, service mode, management mode, supply chain and logistics chain and other innovations. According to the China National Information Center statistics, in 2016, China's sharing economic market transactions amounted to about 3452.2 billion yuan, up 103\% over 2015. In 
2016, China participated in the sharing of economic activities more than 600 million people, of which the number of services provided for 60 million people.

\section{MOBILE-CASE STUDY}

This paper chooses the Mobike case, which is a successful representative of the Sharing economic model. Firstly, the paper introduces the background, operation mode and operation status of Mobike. Secondly, the paper studies the Mobike by PEST model and SWOT model, which analysis eight aspects of politics, economy, society, technology, advantage, weakness, opportunity and threat. Finally, the paper concludes that Mobike has a good development prospect. It also shows that the Internet + sharing economy business model has great application prospect (Tianbo Tang, Xiaojuan Wu, 2015).

\subsection{Company Background}

Mobike founded by $\mathrm{Hu}$ Weiwei, which is a bicycle rental company. Compared to the previous bicycle rental method, it uses a non-pile borrowed bicycle rental mode. Making the rental process easier and more convenient. The company is located to solve the short trip problem.

Each bicycle contains data chips, including the GPS positioning module and SIM card. Customers can quickly find nearby bicycles by Mobike app. Compared to the previous pile of rent models are very different. The customer can park the bicycle in the area of roadside, which are government-defined areas (Wenjing Ge, 2017). Due to the application of Internet technology, the company can carry out real-time monitoring of each bicycle. When the customer ends with a Mobike, the system automatically ends the charge. The model provides great convenience to urban residents for short trips.

In April of 2017, the daily average order volume of the Mobike was stable over 20 million. Mobike has become one of the world's largest and fastest-growing Internet platforms. it has accumulated more than 3.65 million bicycles, which puts more than 100 thousand in single-day. Mobike accounts for $45 \%$ of global bicycle production capacity.

This paper considers that the business model of Mobike is based on the traditional O2O (Online To Offline) model. The $\mathrm{O} 2 \mathrm{O}$ model is to combine offline business activities with the Internet to make the Internet a platform for offline transactions. Mobike is a combination of online and offline business model. Customers use online orders and payments, then getting bicycle offline. The business model of Mobike incorporates a new concept of sharing. This is not only the innovation of the Internet model, but also a great attempt to promote the transformation of the social spirit.

\subsection{PEST Analysis}

In this paper, the development of Mobike is studied from macroscopic aspect by PEST model. This paper analysis the influence of external environmental factors on Mobike from four aspects of politics, economy, society and technology (see Table 1 ).

\subsubsection{Politics}

Political factors refer to political forces which have actual and potential impact on the business activities and the relevant laws, regulations and other factors (Xiangjun Peng, 2010). Most cities are facing traffic problems in China. Traffic problems have almost become one of the most concerned issues for every city government department. The living standard of Chinese residents has improved with the rapid development of China's economy. The number of private cars is increasing in urban areas. Even if there are many regulations in various regions. For example, the restrictions on other region brands were limited, but the problems still could not be fundamentally solved.

Nowadays, the sharing bicycle has helped the government to solve the traffic jam problem. With the promotion of the Internet + sharing business model, many companies help to solve the problems of residents. For example, the Mobike is one of its representatives. It is particularly important that these companies try to subvert the concept of residents. In the survey, the paper found many cases of government cooperation with Internet platforms. For example, the case of Guangzhou Zhuhai district traffic administration and Mobike cooperation is one of its representatives. In the cooperation between the government and the company, the government formulates the corresponding policies by analyzing the background data of Mobike. At the same time, the government departments are responsible for the rational setting of bicycle parking areas. Mobike is mainly responsible for placing bikes on the market. Importantly, in this cooperation, the government has divided the green channel from the urban road planning to the sharing of bicycles. It can be seen that the government departments attach great importance to emerging business models.

\subsubsection{Economy}

Economic factors refer to a country's economic system, economic structure, industrial layout, resource status, level of economic development and future economic trends and so on (Xiangjun Peng, 2010). China's economy has been sustained and rapid development in recent decades. The people's living standards have been improved. And the quality of life requirements are also rising. But in the process of economic development, the density of population increases continuously, which also causes serious traffic problems. According to Amap released the second quarter of 2016 China's major urban traffic analysis report said that traffic problem has become one of the most important factors affecting the quality of life of urban residents. The sharing bicycle can help alleviate the congestion problem of urban traffic.

\subsubsection{Society}

Social factor refers to the organization member's national identity, cultural traditions, values, religious beliefs, educational level, as well as customs and other factors who are in the society (Xiangjun Peng, 2010). The first quarter of 2017 China shared cycling market research report shows that the daily order of Mobike 
more than 20 million. This shows that the sharing economy business model is very popular among consumers. Meanwhile, the catering industry has been subverted by Meituan, Dianping and other companies. And the taxi industry was subverted by Didi Chuxing. Given all above evidence, the paper reasonably reach the conclusion that consumers are highly receptive to new things. This common phenomenon also promoted the rapid development of Internet + sharing business model. In addition, the sharing economy business model also brings a lot of convenience for mankind. Mobike, for example, helps people to solve the last mile of trip.

\subsubsection{Technology}

With the development of mobile Internet technology, smart phones have become an integral part of human life. The development of the Internet also goes from online virtual to offline entity, which gradually improves people's quality of life. Mobike has been developed rapidly, because of the development of Internet technology. In the communications technology, Mobike rely on the use of sports power generation, solar power, GPS positioning, GSM communication, etc. In the industrial technical level, the motorcycles use solid tires, shaft drive, wheel motor, aluminum alloy frame welding process, etc. With the continuous improvement of technology, Mobike will also be favored by consumers.

Table 1 PEST analysis of Mobike

\begin{tabular}{|l|l|}
\hline \multicolumn{1}{|c|}{ Politics } & \multicolumn{1}{c|}{ Economy } \\
$\begin{array}{l}\text { Support Policies } \\
\text { Cooperate with } \\
\text { companies } \\
\text { Government involvement }\end{array}$ & $\begin{array}{l}\text { Emproved levelopment } \\
\text { standards }\end{array}$ \\
\hline \multicolumn{1}{|c|}{ Society } \\
$\begin{array}{l}\text { Concept innovation } \\
\text { Public acceptance }\end{array}$ & $\begin{array}{l}\text { Technology } \\
\text { Internet development } \\
\text { Smart phones penetration }\end{array}$ \\
\hline
\end{tabular}

\subsection{SWOT Analysis}

In this paper, the SWOT model is used to synthesize and generalize the contents of the internal and external conditions of Mobike. And then the paper analysis the advantages and disadvantages of the organization, the opportunities and the threats. (see Table 1).

\subsubsection{Strength}

Mobike is typical of the Internet + sharing business model, which combines online and offline.

The company develops and designs products by itself, which can satisfy consumers' needs through technological innovation. The company develops mobile clients. Consumers can make payments online by their mobile app. Then, consumers can ride a Mobike at anytime and anywhere. The company has different bike types, such as "Lite". It's not only lightweight, but also has a bicycle basket. In addition, some new technologies have been used in "Lite". Consumers feel very comfortable riding "Lite”. Besides, Mobike was added to the booking function. The goal is to avoid customers who could not find a bicycle after online payment. Compared with traditional fixed pile bike, Mobike has no fixed pile, and it is more convenient to ride without limitation.

\subsubsection{Weakness}

Consumers have to pay 299 yuan for a deposit before riding Mobike. Most consumers will hesitate before paying it. At present, Mobike is mainly placed in firsttier cities and second-tier cities. The third-tier and fourth-tier cities are in the development stage, because many practical problems limited. What's more, it is very difficult to ensure that the bicycles are not intentionally destroyed by some people. For example, some people privately give Mobike their own locks, and some people estimate the destruction of quick response codes. In addition, the cost of maintenance is high when the bicycle is put on the market.

\subsubsection{Opportunity}

The concept of green travel has been accepted by consumers, which provided a great opportunity for the development of Mobike. It is very popular among young consumers because of its beautiful appearance. It's nofixed pile parking has attracted a number of users to a certain extent. More importantly, it caters to the development of mobile Internet. After several rounds of funding, the business community has begun to focus on Mobike's development. This provides a great opportunity for its development. In terms of marketing, it has increased customer awareness through the media. In addition, the market share of sharing bicycle is huge in domestic and foreign markets, which has a lot of development space. As of June 2017, the number of sharing bicycle users reached 106 million.

\subsubsection{Threat}

Mobike is a new type of business model. The laws and regulations related to Mobike are not perfect. Mobike's direct competitors are also increasing, such as OFO, U-Bicycle, Mingbike, Bluegogo, etc. Mobike's potential competitors are also increasing, such as sharing "cars" and sharing "electric cars", etc. As more and more competitors enter the sharing bicycle, which brings a huge threat to Mobike. This paper takes OFO bicycle as an example. As of November 2016, OFO has covered 22 cities and over 200 campuses, which has been in the market for only 15 months. At present, the sharing bicycle field is highly competitive. Mobike should continue to improve product services to maintain a strong market competitiveness.

Table 2 SWOT analysis of Mobike

\begin{tabular}{|l|l|}
\hline \multicolumn{1}{|c|}{ Strength } & \multicolumn{1}{c|}{ Weakness } \\
Advanced profit model & Deposit problem \\
Business model & Bicycle damage \\
Technical advantage & Weather factors \\
& High maintenance cost \\
\hline \multicolumn{1}{|c|}{ Opportunity } & \multicolumn{1}{c|}{ Threat } \\
Green concept & Highly competitive \\
Consumer approval & Many substitutes \\
Policy Support & Imperfect law \\
Market potential & \\
\hline
\end{tabular}




\section{PROFIT MODEL INNOVATION}

Mobike uses three profit models during the lead-in period (Jiangang Wang, 2017). Firstly, it can use of "time-sharing lease +deposit" profit model. Through the sub-time leasing makes some funds realized, and the use of deposit to recover the funds. Then, it uses huge capital flows to expand the market. Due to the high cost of operating and maintenance of bicycles and low rental charges, the profit from time-sharing leasing is largely negligible. At this stage, its profit core is in the deposit section. Currently, more than 1 million bicycles have been launched in more than 30 cities in China, driving more than 4 million trips and registering 10 million of users. In the case of 10 million registered users, its deposit is close to 3 billion yuan. Compared with the average Internet company, it collects huge capital flows from the deposit and reduces cash disbursement generated by expanding the huge amount of subsidy. Secondid, Mobike can adopt the advertising profit model. it increases the stickiness of APP users through various activities. Advertising agency on the Sharing cycle app to achieve advertising profit. Finally, it can make use of the big data profit model. it requires real-name registration and payment for its use. The companies and operation platform merchants obtain a large number of accurate user information. On the one hand, these accurate data guide companies make reasonable decisions. On the other hand, these data can be applied to other businesses. When big data is applied to other industries, it is possible to generate new business opportunities and generate more revenue.

Mobike can mainly use two profit models in the growth period. Firstly, the financing expansion of profit model.it can quickly expand the market size by recruitment of capital financing. On the one hand, the cost reduction through scale effect will bring more benefits to Mobike. On the other hand, it beat other competitors to get much profit by expanding finance and market share. Secondly, the service and brand profit model. it provides users with a more intimate service that will be able to stick and get new users with unique user experience. While Mobike continues to accumulate brand value. When the user scale continues to grow and the user has enough user viscosity, it will naturally be able to make a continuous profit.

Mobike to the mature period, the operating conditions are relatively stable. This period of operation scale and operating performance have certain conditions, which can prepare to go public. The final Mobike achieves a virtuous cycle of profitability.

\section{CONCLUSIONS}

At present, the sharing economy covers a wide range of tangible assets and intangible assets. With the development and application of new technologies, more resources will be involved in future sharing economy. In the "Internet +" boom, many companies are actively using sharing business model.

In this context, companies are more and more centered on the customer. The sharing business model will be a great innovation in human business history. The application of Internet technology will further improve the efficiency of business activities. Sharing economy will alleviate the current situation of traffic congestion, because sharing model can make the enterprise in the layout of star distribution. The future development of Internet + sharing business model is not limited to commercial activities, but the business model will contribute to the improvement of social environment.

Based on literature and theory, this paper studies the Internet + sharing business model. The emergence of this new business model has changed the way people spend, which have produced new social and economic benefits. This paper takes Mobike case as the research object and uses PEST model to study the development opportunities of enterprises from the macro perspective. Meanwhile, this paper utilizes the SWOT model to study the advantages, weaknesses, opportunities and threats of Mobike. Then, the profit models of Mobike are analyzed according to the product life cycle theory from the introduction period, the growth period and the maturity stage. Through the analysis of Mobike case, it reveals the strong advantage and development prospect of sharing economy in the background of Internet.

\section{ACKNOWLEDGEMENTS}

This article is very grateful to each anonymous referee for their suggestions and helpful comments on the paper, which helped to improve the presentation of the paper considerably.

\section{REFERENCES}

[1] Russell Belk, 2014. You are what you can access: Sharing and collaborative consumption online, Journal of Business Research. 67(8), pp.1595-1600.

[2] Paul Timmers, 1998. Business models for electronic markets, Electronic Markets. 8(2), pp.3-8.

[3] Min Luo, Liangyu Li, 2015. Business model innovation in the Internet: Based on value creation vision, China Industrial Economics. 1, pp.95-106.

[4] Wenjing Ge, 2017. Construction of sharing bicycle value network model: A case study of Mobike and OFO, China Journal of Commerce. 15, pp.174-176.

[5] Tianbo Tang, Xiaojuan Wu, 2015. Sharing economy: the "Internet+" subversive economic model, Scientific Development. 12, pp.78-84.

[6] Zhiyuan Chen, 2016. Research on innovation and supervision for sharing economy, Management World. 8, pp.176-177.

[7] Jiangang Wang, 2017. Analysis of the profit podel of sharing bicycle, China Journal of Commerce. 11, pp.147-148.

[8] Xiangjun Peng, 2010. Analysis of the bottleneck of mobile E-commerce in Chong Qing based on PEST analytical method, International Conference on E-Business and E-Government IEEE, pp.256-258.

[9] Dubosson, M., Osterwalder, A. and Pigneur, Y, 2002. Ebusiness model design, classification and measurement, Thunderbird International Business Review. 44, pp.5-23.

[10] Yiyun Chen, 2015. Business model: the key to the success of integrated service platform, Journal of China Post.10, pp.3637.

[11] Schumpeter, Joseph Alois, 1939. Business Cycles: a 
Theoretical, Historical and Statistical Analysis of the Capitalist Process. Business cycles: a theoretical, historical, and statistical analysis of the capitalist process, U.M.I. (University Microfilms International) Out-of-Print Books on Demand. pp.223-229.

[12] Amit, Raphael ('Raffi, \& Zott, C.), 2010. Business model innovation: creating value in times of change. Social Science Electronic Publishing.23(23), pp.108-121.

[13] Qin Wang,2011. Company business model innovation based on value network reconstruction, China Industrial Economics. 1, pp.79-88.

[14] Yang Zheng, Li Yu and Jiangwei Liu, 2016. Research on environmental characteristics and development trend of electricity big data, Sci-tech Innovation and Productivity.7, pp.26-28. 